\title{
EFEITO DO EXTRATO AQUOSO DE PRÓPOLIS MARROM SOBRE A PRODUÇÃO DE IFN- $\gamma$ APÓS IMUNIZAÇÃO CONTRA PARVOVÍRUS CANINO (CPV) E CORONAVÍRUS CANINO (CCOV)
}

\author{
EFFECT OF WATER EXTRACT FROM BROWN PROPOLIS ON \\ PRODUCTION OF IFN-y AFTER IMMUNIZATION AGAINST CANINE \\ PARVOVIRUS (CPV) AND CANINE CORONAVIRUS (CCOV)
}

\author{
Maureen Hoch Vieira Fernandes ${ }^{1}$ \\ Lilian das Neves Ferreira $^{1}$ \\ Gilberto D'Avila Vargas² \\ Geferson Fischer² \\ Silvia de Oliveira Hübner² \\ 1Pós-graduandas da Universidade Federal de Pelotas, Pelotas, RS, Brasil - \\ maureenhvfernandes@yahoo.com.br. \\ 2Professores Doutores da Universidade Federal de Pelotas, Pelotas, RS, Brasil.
}

\section{Resumo}

O objetivo deste estudo foi avaliar a capacidade adjuvante imunoestimulatória do extrato aquoso de própolis marrom (EAPM) quando associado a uma vacina contra parvovírus canino (CPV) e coronavírus canino $(\mathrm{CCoV})$, com relação à produção de IFN- $\gamma$. Camundongos foram vacinados com CPV e $\operatorname{CCoV}\left(3,0 \times 10^{6}\right.$ TCDI $\left._{50}\right)$ em associação ou não com $400 \mu \mathrm{g} /$ dose de EAPM. Trinta dias após a terceira dose foi realizado cultivo de esplenócitos para mensuração dos níveis de expressão de mRNA para IFN- $\gamma$ nos animais imunizados. O aumento nos níveis de expressão de mRNA para IFN- $\gamma$ para $\mathrm{CCoV}$ nos esplenócitos dos camundongos inoculados com a vacina contendo 400 $\mu \mathrm{g} /$ dose de EAPM foi evidenciado por RT-PCR, demonstrando a capacidade da própolis em estimular a resposta imune celular contra os antígenos desse vírus. Ao contrário, os níveis de IFN- $\gamma$ para CPV não sofreram influência da presença do EAPM.

Palavras-Chave: adjuvante; coronavírus canino; parvovírus canino; própolis; vacina.

\begin{abstract}
The purpose of this study was to evaluate the imunnostimulatory adjuvant capacity of water extract from brown propolis (WEBP) when added to a vaccine against canine parvovirus (CPV) and canine coronavirus $(\mathrm{CCoV})$, regarding the production of IFN- $\gamma$. Mice were vaccinated with $\mathrm{CPV}$ and $\operatorname{CCoV}\left(3.0 \times 10^{6} \mathrm{TCID}_{50}\right)$ with or without $400 \mu \mathrm{g} /$ dose of WEBP. Thirty days after the third dose, splenocytes were cultured to measure the expression levels of IFN- $\gamma$ mRNA in the immunized animals. Increased levels of IFN- $\gamma$ mRNA expression for CCoV were evidenced by RT-PCR, in the splenocytes of mice inoculated with the vaccine containing $400 \mu \mathrm{g} / \mathrm{dose}$ of WEBP, demonstrating
\end{abstract}


the ability of propolis to stimulate cellular immune responses against the antigens of this virus. In contrast, the levels of IFN- $\gamma$ to CPV were not influenced by the presence of WEBP.

Keywords: adjuvant; canine coronavirus; canine parvovirus; propolis; vaccine.

Recebido em: 02 abril 2013

Aprovado em: 25 fevereiro 2015

\section{Introdução}

Gastroenterites em cães jovens e debilitados são, muitas vezes, associadas a infecções por parvovírus canino $(\mathrm{CPV})$ e/ou coronavírus canino $(\mathrm{CCoV})^{(1,2)}$. A proteção é possível mediante o uso de vacinas que estimulem uma imunidade eficiente e duradoura, por meio da combinação de respostas imunológicas humoral e celular contra o CPV e o CCoV. Contudo, alguns estudos demonstram a baixa eficácia de algumas vacinas inativadas em reduzir a disseminação do $\mathrm{CCoV}$ nas fezes de cães, após contato com o vírus ${ }^{(3)}$. Além disso, há trabalhos que evidenciam a existência de uma grande proporção de cães vacinados para CCoV e CPV soronegativos ou com títulos de anticorpos abaixo do considerado protetor, indicando falha na imunização ${ }^{(4-6)}$. Por conseguinte, busca-se a identificação de novas substâncias que, associadas às vacinas, sejam capazes de resultar na estimulação de uma resposta imunitária adequada, conferindo proteção contra essas enfermidades ${ }^{(7)}$. Nesse sentido, a própolis vem despertando o interesse dos pesquisadores devido à ação imunomodulatória descrita ${ }^{(8,9)}$.

A própolis é um material resinoso coletado pelas abelhas a partir dos exsudatos das plantas, que se transforma na presença de enzimas das abelhas. Sua cor varia do verde, vermelho ao marrom escuro $^{(10)}$. No geral, mais de 300 substâncias já foram identificadas como constituintes da própolis $^{(11)}$, das quais se destacam os polifenóis, tais como os flavonóides, ácidos fenólicos e seus ésteres, aldeídos fenólicos e cetonas ${ }^{(12)}$. Diversas propriedades biológicas como a anti-inflamatória, antimicrobiana e antitumoral ${ }^{(8)}$ já foram descritas. A sua capacidade imunomoduladora, agindo como adjuvante vacinal, tem sido analisada em alguns estudos. Segundo Fischer et al. ${ }^{(9)}$, a própolis, quando usada em conjunto com vacinas de Herpesvírus suíno tipo 1 (SuHV-1), é capaz de aumentar a porcentagem de animais protegidos contra o desafio com uma dose letal, mediante a maior estimulação de resposta imune celular, evidenciada pelo aumento na expressão de mRNA para interferon gama (IFN- $\gamma)$.

Este trabalho descreve a avaliação de efeito adjuvante vacinal do extrato aquoso de própolis marrom em uma vacina múltipla contendo CPV e CCoV, por meio da mensuração da produção de mRNA para IFN- $\gamma$, como forma de analisar a resposta celular induzida após vacinação.

\section{Material e Métodos}

A própolis marrom foi disponibilizada pela Apis Nativa Produtos Naturais Indústria e Comércio Ltda. (Brasil). O extrato aquoso foi obtido após trituração e extração feita em água destilada a $70{ }^{\circ} \mathrm{C}$ sob agitação, por 12 horas. Após filtração, o extrato aquoso foi liofilizado (Edwards High Vaccum). A matéria seca obtida foi ressuspendida em meio essencial mínimo (DMEM, SIGMA), numa 
concentração final de $100 \mathrm{mg} / \mathrm{mL}$, e esterilizada em filtro Millipore (22 micras).

Foram utilizados 90 camundongos Swiss (Mus musculus) fêmea, com quatro a seis semanas de idade, provenientes do Biotério Central da Universidade Federal de Pelotas. Os animais permaneceram isolados, em ambiente controlado com temperatura entre $22-24{ }^{\circ} \mathrm{C}$, recebendo comida e água ad libitum A eutanásia seguiu as normas estabelecidas pela resolução de número 714, de 20 de junho de 2002, do Conselho Federal de Medicina Veterinária ${ }^{(13)}$. A condução do experimento se deu em junho de 2008.

Uma vacina comercial contendo antígenos múltiplos para caninos foi utilizada para avaliação do efeito imunomodulador da resposta celular (adjuvante) do extrato aquoso de propólis marrom. A vacina continha sete antígenos vivos atenuados, incluindo o parvovírus canino (CPV), e um diluente contendo o antígeno de coronavírus canino $(\mathrm{CCoV})$, inativado por irradiação ultravioleta e adsorvido ao hidróxido de alumínio. Os camundongos foram divididos aleatoriamente em 9 grupos de dez animais. Os grupos 1, 2 e 3 (controles negativos), foram inoculados com solução salina tamponada (PBS) acrescida de $400 \mu \mathrm{g} /$ dose de própolis marrom. Os grupos 4, 5 e 6 receberam apenas vacina comercial contendo $3,0 \times 10^{6} \mathrm{TCDI}_{50}$ (doses infectantes para 50\% dos cultivos celulares). Os animais dos tratamentos 7,8 e 9 receberam doses da vacina $\left(3,0 \times 10^{6}\right.$ TCDI $\left._{50}\right)$ acrescidas de $400 \mu \mathrm{g} /$ dose do extrato aquoso de própolis marrom. Foram realizadas três inoculações por via subcutânea, com intervalo de 30 dias, na região pré-escapular. Trinta dias após a terceira inoculação, quatro animais de cada grupo foram eutanasiados e esplenectomisados, e o cultivo de esplenócitos foi realizado para mensuração dos níveis de expressão de mRNA para IFN- $\gamma$.

Os níveis de expressão mRNA IFN- $\gamma$ nos esplenócitos dos camundongos foram usados como parâmetros para avaliação da resposta imune celular, metodologia já utilizada em outros estudos semelhantes ${ }^{(9,14)}$. Os esplenócitos foram processados de acordo com Bastos et al. ${ }^{(15)}$. Em suma, um "pool" de esplenócitos foi obtido a partir do baço de quatro animais de cada tratamento, 30 dias após a terceira inoculação. Após a lise dos eritrócitos com cloreto de amônio $\left(\mathrm{NH}_{4} \mathrm{CL}-0,85 \%\right)$, os esplenócitos foram semeados numa concentração de $10^{7}$ células/mL em DMEM (SIGMA, EUA), suplementado com $10 \%$ de soro fetal bovino (SIGMA, EUA), em placa de cultivo celular com 96 cavidades. Após 24 horas de incubação a $37{ }^{\circ} \mathrm{C}$ em ambiente com $5 \%$ de $\mathrm{CO}_{2}$, o sobrenadante foi removido e as células estimuladas em quadruplicata com DMEM (controle negativo), 0.1 MOI (multiplicidade de infecção) de CPV, $0.1 \mathrm{MOI}$ de $\mathrm{CCoV}$ ou $5 \mu \mathrm{g} / \mathrm{mL}$ de Concanavalina A (controle positivo). Quarenta e oito horas após a estimulação, as células foram congeladas em Trizol (Invitrogen) para extração de RNA total, de acordo com protocolo do fabricante. A síntese de cDNA foi realizada com $5 \mu \mathrm{g}$ de RNA total em uma reação de $25 \mu \mathrm{L}$, contendo $0,5 \mu \mathrm{L}$ (150 ng) de random primers (Invitrogen), $1 \mu \mathrm{L}$ de trifosfato de desoxinucleosideo (dNTP $-10 \mathrm{mM})$, "first strand buffer" 1x (Invitrogen), 0,1 M DTT, $40 \mathrm{U}$ de "RNaseOUT" (Invitrogen) e $50 \mathrm{U}$ da enzima transcriptase reversa M-MuLV (New England Biolabs), segundo metodologia previamente descrita por Ulett et al. ${ }^{(16)}$. As amostras foram, então, incubadas a $25^{\circ} \mathrm{C}$ por 10 minutos, seguido de $42{ }^{\circ} \mathrm{C}$ durante 50 minutos e $70^{\circ} \mathrm{C}$ por 15 minutos, em termociclador Eppendorf Mastercycler Gradient. O cDNA resultante foi armazenado a $-20{ }^{\circ} \mathrm{C}$. As reações de PCR foram executadas com $2 \mu \mathrm{L}$ de cDNA, $200 \mu \mathrm{M}$ de dNTPs, tampão da enzima Taq 1x, $1.5 \mathrm{U}$ da enzima Taq DNA polimerase (Ludwig Biotec), $1 \mu \mathrm{M}$ de cada primer, $\mathrm{MgCl} 2(1.5 \mathrm{mM})$, além de água livre de RNase (Gibco$\mathrm{BRL}$ ), em um volume final de $25 \mu \mathrm{L}$. Os parâmetros usados para a PCR foram os seguintes: $95^{\circ} \mathrm{C}$ por dois minutos, seguidos de 30 ciclos de $94{ }^{\circ} \mathrm{C}$ durante 50 segundos, $60{ }^{\circ} \mathrm{C}$ por 50 segundos e 72 ${ }^{\circ} \mathrm{C}$ por um minuto, com extensão final de $72{ }^{\circ} \mathrm{C}$ por sete minutos. Os primers utilizados ${ }^{(16)}$ foram 
sintetizados por MWG-Biotech Inc. (USA): IFN- $\gamma$ "forward" 5'AGCGGCTGACTGAACTCAGATTGTAG; IFN- $\gamma \quad$ "reverse" GTCACAGTTTTCAGCTGTATAGGG; $\quad \beta$-actina $\quad$ "forward TGGAATCCTGTGGCATCCATGAAAC; $\quad \beta$-actina $\quad$ "reverse" TAAAACGCAGCTCAGTAACAGTCCG. Reações de PCR usando primers para $\beta$-actina, bem como reações sem cDNA foram realizadas como controle. Os produtos da PCR foram visualizados sob luz ultra-violeta, após eletroforese em gel de agarose a $2 \%$ contendo brometo de etídio.

A avaliação da expressão de mRNA para IFN- $\gamma$ e $\beta$-actina foi realizada mediante a comparação entre as intensidades das bandas obtidas. Dados de densitometria para as intensidades de bandas foi gerado por análise das imagens de gel sobre o programa ImageJ® (Rasband, W.S., ImageJ, U. S. National Institutes of Health, Bethesda, Maryland, USA, 1997-2014). As áreas dos picos correspondentes aos valores de densitometria obtidas pelo programa reproduzem efetivamente as intensidades das bandas obtidas em cada amostra.

\section{Resultados e Discussão}

A relação positiva entre o título de anticorpos no soro do animal e o nível de proteção contra algumas infecções já foram estabelecidas ${ }^{(4)}$; no entanto, embora componentes da resposta imune inata e anticorpos possam neutralizar virions livres e destruir células infectadas, as respostas imunológicas mediadas por células têm se mostrado fundamentais para a eficaz resolução de infecções virais ${ }^{(17)}$. Uma forma de mensurar a resposta celular induzida por uma vacina é avaliando a produção de IFN- $\gamma$, conhecido também como interferon imune, pelos linfócitos. O IFN- $\gamma$ age como potente ativador de macrófagos induzindo-os na secreção de óxido nítrico e citocinas, ativa neutrófilos, células natural killers e células endoteliais vasculares, e atua diretamente sobre os linfócitos B e T, estimulando a diferenciação celular e promovendo a atividade das células Th1 ${ }^{(18)}$. $\mathrm{O}$ uso de vacinas associadas à imunoestimulantes vem sendo avaliado como uma abordagem inovadora no desenvolvimento de novos tipos de adjuvantes ${ }^{(19)}$. Nesse sentido, quando utilizada junto a uma vacina, a própolis pode aumentar a segurança da vacina associada, aumentando o seu índice de proteção e reduzindo a concentração da dosagem ótima ${ }^{(20)}$. O adjuvante ideal precisa ser estável, biodegradável, com baixo custo e deve promover uma resposta imune celular e ou humoral apropriada, dependendo do tipo de proteção requerida ${ }^{(21)}$. Alguns estudos mostraram que a própolis é capaz de agir como adjuvante imunoestimulante, tendo capacidade de melhorar a resposta imune. Seus componentes aumentaram os títulos de anticorpos neutralizantes ${ }^{(22)}$, ativaram a fagocitose, aumentaram os níveis de IFN- $\gamma$ e o número total de linfócitos ${ }^{(23,24)}$. A potencialidade como adjuvante da própolis também foi demonstrada em uma vacina de DNA ${ }^{(25)}$.

No presente estudo, a adição do extrato aquoso de própolis marrom (400 $\mu \mathrm{g} / \mathrm{dose})$ à vacina não resultou em um aumento na expressão de mRNA para IFN- $\gamma$ para o CPV nos esplenócitos dos camundongos vacinados (Figura 1). Contudo, como demonstrado na Fig. 2, os níveis de expressão de mRNA para IFN- $\gamma$ foi maior nos camundongos estimulados com CCoV quando vacinados com a adição do extrato aquoso de própolis, fato evidenciado pela maior intensidade da banda obtida. 


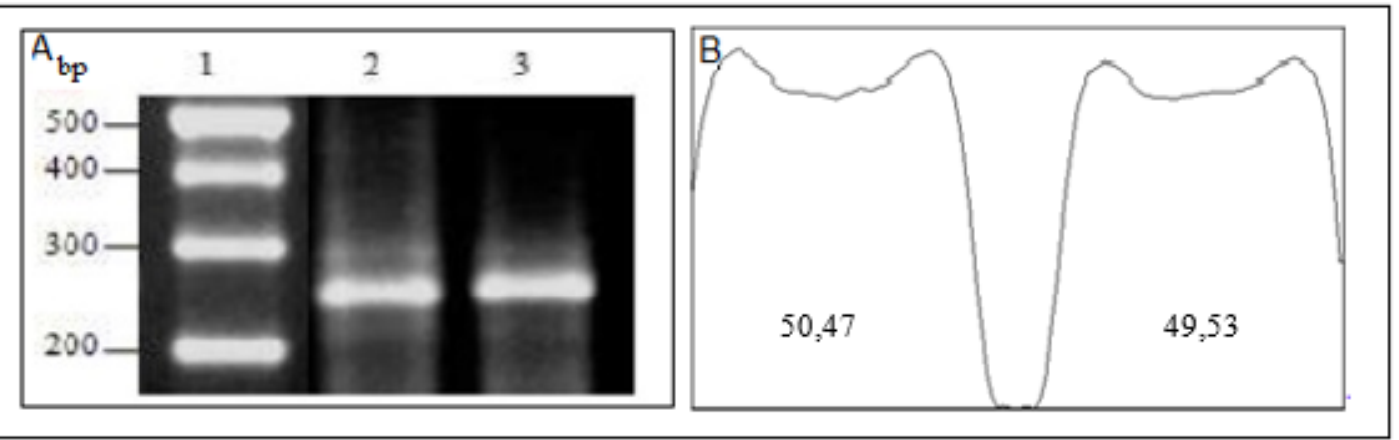

Figura 1: A - Produtos de RT-PCR em gel de agarose resultantes da amplificação de mRNA para IFN- $\gamma$ de esplenócitos de camundongos, coletados 30 dias após a terceira dose de vacina com ou sem própolis. Análise 48 horas após estimulação com 0,1 MOI de CPV: 1, GeneRuler 100 pb DNA

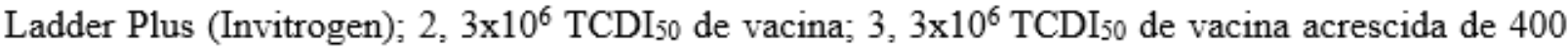
$\mu \mathrm{g}$ de própolis marrom. B - Análise densitométrica das bandas obtidas pelo programa ImageJ®.

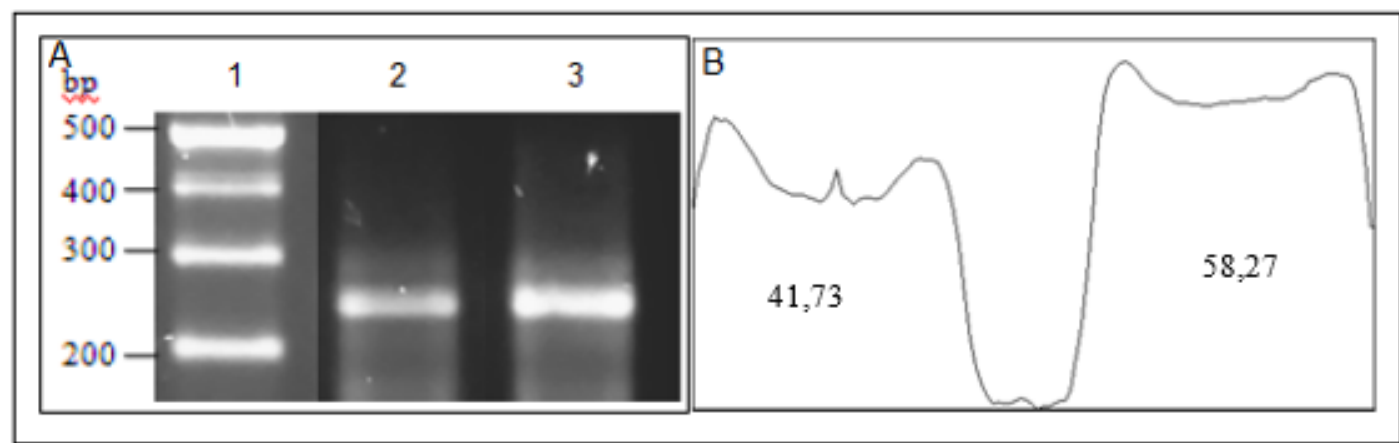

Figura 2: A - Produtos de RT-PCR em gel de agarose resultantes da amplificação de mRNA para IFN- $\gamma$ de esplenócitos de camundongos, coletados 30 dias após a terceira inoculação de vacina com ou sem própolis. Análise 48 horas após estimulação com $0,1 \mathrm{MOI}$ de CCoV: 1, GeneRuler $100 \mathrm{pb}$

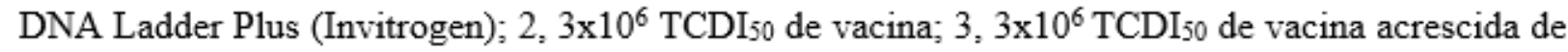
$400 \mu \mathrm{g}$ de própolis marrom. B - Análise densitométrica das bandas obtidas pelo programa ImageJ®.

O mecanismo de ação que a própolis exerce sobre as células do sistema imune ainda não foi completamente elucidado; no entanto, sabe-se que seus diferentes compostos agem de diversas maneiras ${ }^{(26)}$. Destaca-se a importância dos polifenóis ${ }^{(27)}$, que estimulam a proliferação de linfócitos, e dos flavonóides, que incitam a produção de algumas citocinas responsáveis pela mitose de linfócitos, tais como interleucina 1 (IL-1) e interleucina 2 (IL-2) ${ }^{(28)}$. No entanto, de acordo com os resultados obtidos, supõe-se que a própolis direciona o sistema imune para um tipo de resposta conforme o antígeno presente na vacina. Ferreira et al. ${ }^{(7)}$ já descreveram essa possibilidade quando identificaram um aumento na produção de anticorpos para CPV e nenhum acréscimo para CCoV, após usar um outro tipo de extrato de própolis como adjuvante vacinal. Considera-se que o sistema imune pode gerar diferentes respostas de acordo com o tipo de antígeno apresentado, sendo a diferenciação dos linfócitos T CD4+ em consequência da apresentação das células apresentadoras de antígeno e das citocinas secretadas no momento. A diferenciação em linfócito Th1 é responsável por gerar a resposta imune celular, e a diferenciação em Th2 pela resposta imune humoral ${ }^{(29)}$; além 
disso, os linfócitos ainda podem se diferenciar em Th17, que contribuem na resposta a doenças auto-imunes e alergias ${ }^{(30)}$, e Treg, essenciais para a manutenção da tolerância periférica e para limitar as respostas inflamatórias excessivas ${ }^{(31)}$. Dessa forma, é possível que a própolis combinada com os antígenos de $\mathrm{CCoV}$ inativados presentes na vacina seja capaz de estimular a diferenciação de células T CD4+ em, principalmente, células Th1, que são as principais células responsáveis pela secreção de IFN- $\gamma$, agindo primordialmente na resposta imune celular, enquanto os antígenos de $\mathrm{CPV}$, que são atenuados, combinados com a própolis induzam a outro tipo de resposta imune. É possível que essa influência ocorre devido à estimulação de determinadas moléculas receptoras presentes nas células apresentadoras de antígenos, capazes de conduzir antígenos específicos para determinado tipo de apresentação, podendo ser exógena ou endógena, influenciando o tipo de resposta a ser formado ${ }^{(32)}$.

\section{Conclusões}

Os resultados encontrados nesse estudo demonstram atividade adjuvante do extrato aquoso de própolis marrom frente ao $\mathrm{CCoV}$ quando associado a uma vacina múltipla administrada em camundongos. Esse efeito imunoestimulatório foi claramente percebido devido ao aumento nos níveis de IFN- $\gamma$, citocina que evidencia o aumento da imunidade celular. O extrato não foi capaz de aumentar os níveis de IFN- $\gamma$ para CPV nos esplenócitos dos camundongos vacinados, sugerindo que a ação imunoestimulatória da própolis depende do tipo de antígeno usado. $\mathrm{O}$ uso da própolis como adjuvante imunoestimulador pode contribuir para a geração de vacinas capazes de produzir proteção eficiente contra agentes infecciosos virais frequentes causadores de doença em cães, tal como o coronavírus canino $(\mathrm{CCoV})$, sendo que as atuais vacinas comerciais são de eficácia relativa. Novos estudos são necessários para avaliar em caninos a resposta do extrato de própolis marrom como adjuvante vacinal.

\section{Referências}

1. Decaro N, Buonavoglia C. An update on canine coronaviruses: Viral evolution and pathobiology. Veterinary Microbiology. 2008;132(3-4):221-234.

2. Hoelzer K, Parrish C. The emergence of parvoviruses of carnivores. Veterinary Research. 2010;41(6):39.

3. Pratelli A, Tinelli A, Decaro N, Cirone F, Elia G, Roperto S, Tempesta M, Buonavoglia C. Efficacy of an inactivated canine coronavirus vaccine in pups. New Microbiologica. 2003;26(2):151-155.

4. Elia G, Cavalli A, Cirone F, Lorusso E, Camero M, Buonavoglia D, Tempesta M. Antibody levels and protection to canine parvovirus type 2. Journal of Veterinary Medicine B. 2005;52:320-322.

5. Hass R, Johann JM, Caetano CF, Fischer G, Vargas GD, Vidor T, Hübner SO. Antibodies levels against canine distemper virus and canine parvovirus in vaccinated and unvaccinated dogs. Arquivo Brasileiro de Medicina Veterinária e Zootecnia [online]. 2008;60(1):270-274.

6. Castro CC, Johann JM, Finger PF, Nunes CF, Vargas GD, Fischer G, Hübner SO. Canine coronavirus $(\mathrm{CCoV})$ in dogs vaccinated and unvaccinated domiciliated in Pelotas, RS, Brazil. Semina:Ciências Agrárias (Impresso). 2010;31(4):995-1000.

7. Ferreira LN, Finger PF, Castro CC, Siedler BS, Munhoz LS, Vargas GD, Fischer, G, Hübner SO. Effect of the ethanolic extract from green propolis on production of antibodies after immunization against canine parvovirus and canine coronavirus. Brazilian Journal of Veterinary Research and Animal Science. 
2012;49:116-21.

8. Bankova V, Castro SL, Marcucci MC. Propolis: recent advances inchemistry and plant origin. Apidologie. 2000;31:3-15.

9. Fischer G, Conceição FR, Leite FPL, Dummer LA, Vargas GD, Hübner SO, Dellagostin OA, Paulino N, Paulino AS, Vidor T. Immunomodulation produced by a green propolis extract on humoral and cellular responses of mice immunized with SuHV-1.Vaccine. 2007;25:1250-56.

10. Burdock GA. Review of the biological properties and toxicity of bee propolis (propolis). Food and Chemical Toxicology. 1998;36:347-63.

11. De Castro SL. Propolis: Biological and Pharmacological Activities. Annual Review of Biomedical Sciences. 2001;3:49-83.

12. Dobrowolski JW, Vohora SB, Kalpana S, Shah SA, Naqvi SAH, Dandiya PC. Antibacterial, antifungal, antiamoebic, antiinflammatory and antipyretic studies on propolis bee products. Journal of Ethnopharmacol. 1991;35:77-82.

13. Conselho Federal de Medicina Veterinária. Resolução nº 714, de 20 de JUNHO de 2002. Procedimentos e métodos de eutanásia em animais. Disponível em: http://www.usp.br/bioterio/Artigos/Eutanasia/resolucao_714.pdf. Acesso em 23 de março de 2015.

14. Sá-Nunes A, Faccioli LH, Sforcin JM. Propolis: lymphocyte proliferation and IFN- $\gamma$ production. Journal of Ethnopharmacology. 2003;87:93-7.

15. Bastos RG, Dellagostin OA, Barletta RG, Doster AR, Nelson E, Osorio FA. Construction and immunogenicity of recombinant Mycobacterium bovis BCG expressing GP5 and M protein of porcine reproductive respiratory syndrome virus. Vaccine. 2002;21:21-9.

16. Ulett GC, Ketheesan N, Hirst RG. Cytokine gene expression in innately susceptible Balb/c mice and relatively resistant $\mathrm{C} 57 \mathrm{BL} / 6$ mice during infection with virulent Burkholderia pseudomallei. Infection and Immunity. 2000;68(4):2034-42.

17. Dewitt WS, Emerson RO, Lindau P, Vignali M, Snyder TM, Desmarais C, Sanders C, Utsugi H, Warren EH, McElrath J, Makar KW, Wald A, Robins HS. Dynamics of the Cytotoxic T Cell Response to a Model of Acute Viral Infection. Journal of Virology. 2015;89(8):4517-26.

18. Gattoni A, Parlato A, Vangieri B, Bresciani M, Derna R. Interferon-gamma: biologic functions and HCV terapy (type I/II) (2 of 2 parts). La Clinica Terapeutica. 2006;157(5):457-68.

19. Gautam M, Gairola S, Jadhav S, Patwardhan B. Ethnopharmacology in vaccine adjuvant discovery. Vaccine. 2008;26:5239-40.

20. Ashry SH, Ahmad TA. The use of propolis as vaccine's adjuvant. Vaccine. 2012;31:31-9.

21. Aguilar JC, Rodriguez EG. Vaccine adjuvants revisited. Vaccine. 2007;25:3752-62.

22. Fischer G, Cleff MB, Dummer LA, Paulino N, Paulino AS, Vilela CO, Campos FS, Storch T, Vargas DG, Hübner SO, Vidor T. Adjuvant effect of green propolis on humoral immune response of bovines immunized with bovines herpesvirus type 5. Veterinary Immunology and Immunopathology. 2007;116:7984.

23. Mu Y, Zhou L, Lu J, Li N, Li Y, Huang Q. Effect of different adjuvant for Newcastle Disease vaccine on humoral immunity in chicken. Chin Poultry. 2007;19. Disponível em: http://en.cnki.com.cn/Article_en/CJFDTOTAL-ZGJQ200719005.htm. Acesso em 23 de março de 2015.

24. Yuan J, Liu J, Hu Y, Fan Y, Wang D, Guo L, Nguyen TL, Zhao X, Liu X, Liu C, Wu Y. The immunological activity of propolis flavonoids liposome on the immune response against ND vaccine. International Journal of Biological Macromolecules. 2012;51:400-5.

25. Yu L, Li J, Huang Y, Li L. Polyprotein (VP2/VP4/VP3) gene of infectious bursal disease virus, its eukaryotic expression plasmid and use thereof as DNA vaccine. Faming Zhuanli Shenqing Gongkai Shuomingshu. 2004; CN 1467293 A 20040114 [Chinese].

26. Ansorge S, Reinhold D, Lendeckel U. Propolis and some of its constituents down-regulate DNA synthesis and inflammatory cytokine production but induce TGF-b1 production of human immune cells. Z 
Naturforsch. 2003;58c:580-9.

27. Castaldo S, Capasso F. Propolis: an old remedy used in modern medicine. Fitoterapia. 2002;1:S1-S6.

28. Havsteen BH. The biochemistry and medical significance of the flavonoids. Pharmacology \& Therapeutics. 2002;96:67-202.

29. Machado PRL, Araújo MIAS, Carvalho L, Carvalho EM. Mecanismos de resposta imune às infecções. Anais Brasileiros de Dermatologia. 2004;79(6):647-64.

30. Glosson-Byers NL, Sehra S, Stritesky GL, Yu Q, Awe O, Pham D, Bruns HA, Kaplan MH. Th17 cells demonstrate stable cytokine production in a proallergic environment. Journal of immunology. 2014;193(6):2631-40.

31. Van der Veeken J, Arvey A, Rudensky A. Transcriptional control of regulatory T-cell differentiation. Cold Spring Harbor symposia on quantitative biology. 2013;78:215-22.

32. Guermonprez P, Valladeau J, Zitvogel L, Théry C, Amigorena S. Antigen presentation ant T cell stimulation by dendritic cells. Annual Review of Immunology. 2002;20:621-67. 